\title{
The University of Missouri Regional Biocontainment Laboratory - What It Is and the Emphasis on Regional
}

\author{
George Stewart
}

McKee Professor of Microbial Pathogenesis and Chairman, Department of Veterinary Pathology, University of Missouri

$\mathrm{I}$

you build it, he will come

W. P. Kinsella (Shoeless Joe, Houghton Mifflin, 1982)

Concerns over bioterrorism, emerging infectious diseases, and food safety and security led to the creation of a regional network of biosafety level 3 facilities in the United States. These facilities provide safe environments for conducting research on high consequence bacterial and viral pathogens. The facilities were expensive to build and will be expensive to operate. They do, however, provide unique opportunities for researchers throughout the country to conduct research programs that are not possible without the specialized containment laboratories. To be economically viable, the biocontainment labs must be maximally utilized. This necessitates that Universities that host these facilities create an environment that encourages and facilitates collaborative and cooperative research agreements with regional research institutions.

\section{Introduction}

Contemporary scientific research often involves the use of expensive equipment and facilities. When universities make a commitment to provide these facilities, the decision not only involves an up-front expenditure of often scarce resources, but programmatically commits the university to very specific research directions. Prior to having the specialized facilities, it is unlikely that a critical mass of faculty will exist who work in that research arena, because of the very lack of those facilities. The newly constructed facilities, or expensive equipment, thus become the "Field of Dreams" with the expectation that researchers who can exploit the resources will be identified. Some may be recruited to the University, other users as collaborators or users of the facilities on a fee-for-service basis.

This model has been quite successfully applied in certain scientific disciplines, most notably physics, where the costs of particle colliders, cyclotrons, and nuclear reactors are beyond the scope of most university budgets. Physicists at Universities lacking these facilities book time on these instruments and then spend the bulk of the year analyzing the data back at their home institution. Biologists, as a general rule, tend not to think regionally when it comes to their individual research 
programs. For example, Midwestern schools lack research programs in marine biology, despite being ideally situated equidistant from the Pacific and Atlantic Oceans. We do not seek out time-sharing options with institutions which have the ships and equipment to conduct this type of research (i.e. Scripts and Woods Hole Oceanographic Institutions). Modern research in molecular biology is increasingly dependent on the use of expensive equipment and specialized facilities. Will biologists follow the lead of our physicist colleagues and make use of regional or national resources? This will soon be put to the test with the construction of the national network of Regional Biocontainment Laboratories.

\section{The RBL Network}

The anthrax postal (Amerithrax) bioterrorism events in the fall of 2001 raised bioterror concerns in the US and worldwide ${ }^{1}$ In February 2002, consultations between the National Institute of Allergy and Infectious Diseases (NIAID) and its Blue Ribbon Panel on Bioterrorism produced several recommendations for NIAID to better protect the American public from the threat of bioterrorism. One recommendation was to create more laboratory space for work with dangerous pathogens. A request for proposals was issued to create a regional network of biosafety level 3 laboratories (Regional Biocontainment Laboratories [RBLs]) and biosafety level 4 facilities (National Biocontainment Laboratories [NBLs] $^{2}$. Two NBLs were ultimately created, one in Boston, MA and the other in Galveston, TX. Thirteen RBLs were created in this program (Figure 1). NIH provided $75 \%$ of the construction costs for the RBLs and the remainder of the construction costs was provided by the host institution or state. The grantees in turn agreed to operate the biocontainment labs for a period of twenty years. The two NBLs, with the highest level of biocontainment (BSL-4), receive operation support through the $\mathrm{NIH}$ awards and are facilities that can handle exceedingly dangerous pathogens for which there is no vaccine or therapy available. The RBLs, are BSL3 facilities which are designed for work on pathogens that are transmitted by the aerosol route, have significant mortality rates, but for which vaccines or treatments are available. The $\mathrm{NIH}$ provided construction costs for the RBLs, but made it clear that operating costs for them was not to be part of this program. The Biosecurity Research Institute (BRI) at Kansas State University was not part of the NIH program, but is included in this discussion because of its unique attributes relative to the other containment facilities.

Microbial pathogens that are of concern as agents of bioterrorism, are part of the federal government's Select Agent program, and research on these agents require BSL-3 containment facilities $^{3}$. The select agent pathogens include a variety of bacterial, viral pathogens that share the property of being transmissible by the aerosol route. Examples include the agent of anthrax (Bacillus anthracis), plague (Yersinia pestis), tularemia (Francisella tularensis), and St. Louis Encephalitis Virus. Prior to 2001, research on virulent strains of $B$. 


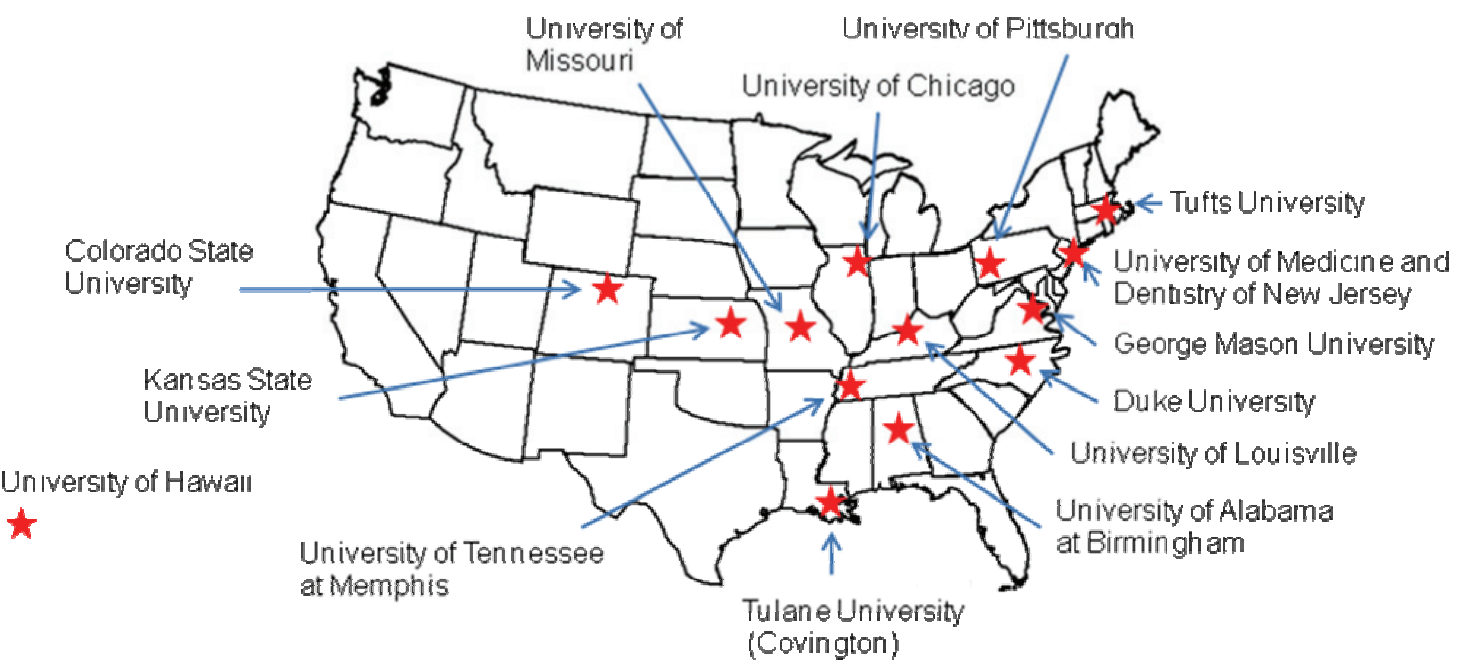

\begin{tabular}{|l|l|l|l|}
\hline BSL-3 Facility & Location & $\begin{array}{l}\text { Approximate Gross } \\
\text { Square Footage }\end{array}$ & Estimated Cost \\
\hline Colorado State University RBL & Ft. Collins, CO & 33,850 & $\$ 30$ million \\
\hline $\begin{array}{l}\text { George Mason University } \\
\text { Biomedical Research Laboratory }\end{array}$ & Fairfax, VA & 53,000 & $\$ 48$ million \\
\hline $\begin{array}{l}\text { Howard T. Ricketts RBL } \\
\text { (University of Chicago) }\end{array}$ & Chicago, IL & 35,000 & $\$ 31$ million \\
\hline $\begin{array}{l}\text { Kansas State University } \\
\text { Biosecurity Research Institute }\end{array}$ & Manhattan, KS & 113,000 & $\$ 54$ million \\
\hline $\begin{array}{l}\text { New England Regional Biosafety } \\
\text { Laboratory (Tufts University) }\end{array}$ & Boston, MA & 41,000 & $\$ 33.7$ million \\
\hline $\begin{array}{l}\text { Pacific RBL } \\
\text { University of Hawaii }\end{array}$ & Honolulu, HI & 25,000 & $\$ 47.5$ million \\
\hline RBL at Duke University & Durham, NC & 33,145 & $\$ 22.4$ million \\
\hline $\begin{array}{l}\text { Southeast Biosafety Laboratory } \\
\text { (Univ. Alabama at Birmingham) }\end{array}$ & Birmingham, AL & 43,500 & $\$ 32$ million \\
\hline Tulane University RBL & Covington, LA & 38,000 & $\$ 27.5$ million \\
\hline $\begin{array}{l}\text { University of Medicine \& Dentistry } \\
\text { Of New Jersey RBL }\end{array}$ & Newark, NJ & 34,700 & $\$ 39$ million \\
\hline $\begin{array}{l}\text { University of Louisville Center for } \\
\text { Preventive Medicine }\end{array}$ & Louisville, KY & 37,000 & $\$ 34.6$ million \\
\hline University of Missouri & Columbia, MO & 32,500 & $\$ 28$ million \\
\hline University of Pittsburgh RBL & Pittsburgh, PA & 20,000 & 30,315 \\
\hline $\begin{array}{l}\text { University of Tennessee Health } \\
\text { Science Center RBL }\end{array}$ & Memphis, TN & million \\
\hline
\end{tabular}

anthracis could be conducted at the research on this pathogen requires the lower biocontainment level, BSL-2, more specialized and expensive BSL-3 which is more typical of the level of containment. Thus reclassification of typical University medical microbiology biosafety conditions, in addition to an laboratories. However, with inclusion of increased emphasis on biodefenseB. anthracis on the select agent list, related research, created the increased 
demand for biocontainment research laboratories.

The RBLs support NIAID-funded biodefense and emerging infectious diseases research and are members of the NIAID Biodefense Network. Additionally, the RBLs serve as regional resources for research institutions in the area, and would be available and prepared to assist national, state, and local public health efforts in the event of a bioterrorism emergency. At the same time as the RBL construction grant program, NIAID held a competition to establish a network of Regional Centers of Excellence for Research in Biodefense and Emerging Infectious Diseases (RCEs) ${ }^{4}$. Although the RBL construction grant program was distinct form the RCE program, the RBLs have in many cases formed an alliance with the RCEs and provide an important source of biocontainment research space for the RCE research projects.

The RBLs are intended to be regional resources, although the majority of them are concentrated in the eastern half of the United States. The Universities hosting the RBLs fall into a spectrum of experience in research programs related to high containment pathogens. At one end of the spectrum was Colorado State University, which had large established biosafety level 3 programs in tuberculosis and arthropodborne viruses. Construction of the RBL permitted them to expand their heavily utilized facilities and further build these research programs. The existing programs at Colorado State meant that at the time of the RBL construction, investigators and projects going into the new space were already largely identified.

At the other end of the spectrum were Kansas State University, the University of Louisville and the University of Missouri that at the time of the awarding of the RBL grants, had either no biosafety level 3 laboratory space or had small individual laboratories. Existing faculty with need for these facilities were not present at these universities at the time of the RBL grant submissions or were present in too small a number to utilized the newly constructed research space. Without the specialized facilities, no existing projects were in place in these institutions. Thus the RBLs were built with the intention that biocontainment-requiring programs would have to be established de novo.

The Kansas State University Biosecurity Research Institute is unique among the biocontainment laboratories in that it is a BSL-3Ag facility, specifically designed to permit research on larger animals, specifically food animals. It is the only facility listed above which can study zoonotic infections involving cattle, sheep, goats, and swine. It is a remarkable facility that can contribute substantially to our understanding of zoonotic diseases and food safety. Although Kansas State had strong research programs in food safety and security, at the time the University completed construction of the BRI, it had no active BSL-3 or BSL-3Ag research programs. However, the facility has already paid dividends for the University as the presence of the BRI has been cited as one factor in the selection of the Manhattan, KS site for the Department of Homeland Security's 
National Agro- and Biodefense Facility (NBAF), a biosafety level 3 and 4 facility for research on foreign animal diseases and zoonoses to replace the aging Plum Island Animal Disease Center. Construction of NBAF will create a $500,000 \mathrm{sq} \mathrm{ft}$. facility dedicated to the study of zoonotic and foreign animal diseases and will provide an influx of infectious disease expertise to the Midwest. However, Kansas State, like the other Universities hosting RBLs, must internally build up its research programs in infectious diseases to make optimal use of their new facilities.

Challenges to internally building biocontainment research programs

Biocontainment facilities are expensive to build, especially with the requirement for redundant safety features. They are additionally expensive to operate. Their energy costs are greater than conventional laboratory buildings. They require a special work force of highly trained individuals to provide for the increased security and maintenance aspects of the building. The need for a larger and more highly trained work force for biocontainment facilities drives up personnel costs. Many of these expenses are fixed, and thus operating the facility at $50 \%$ capacity is not significantly less expensive than operating it at full capacity. Thus the only way that these facilities will not be an economic drain on the Universities is to have them operating at capacity and the research projects bringing in revenue in the form of grants and contracts to the host institutions. It is critical that Universities, once they commit to operating biocontainment facilities, recruit faculty specifically to the facilities. These faculty could be recruited to different departments at the University (such as Biology, Biochemistry, Microbiology, etc). However, usually it is a specific group or department that was the driving force in the development of the proposal for the RBL, and other departments did not necessarily buy in to this specific research direction for the University. Because of chronically tight budgets, new faculty hires are limited at the Universities. Many departments opt not to recruit with the RBL in mind. This may be due to specific programmatic or teaching needs for the individual department. Another potential concern, however, is economic. With universities committed to operating the RBLs or the BRI, funding sources to operate these facilities will have to come from overly stretched budgets. Adding a faculty member who utilizes the facility might target that department for providing funds for operational costs. At least that is the fear shared by heads of the departments. As a consequence, for many of the RBLs and the BRI, very few faculty researchers have actually been recruited to staff the biocontainment laboratories and to write grants to support operation of the facilities. Most of these facilities will be markedly under-utilized at the time they acquire the requisite certifications to begin BSL-3 and Select Agent Program operations.

The addition of faculty after the facilities become operational, improves the situation but takes time before the newly hired researchers can contribute. The faculty, and whatever postdoctoral, student, and technical staff they hire, 
must undergo Department of Justice background checks and extensive training before they can begin working under biosafety level 3 conditions. Research projects must be approved by University Compliance committees (the Institutional Biosafety Committee [IBC] and the Animal Care and Use Committee [ACUC]) as well as obtaining CDC or USDA authorization for select agent-related activities. These are timeconsuming processes that can delay the initiation of research projects by many months. Only after all of the compliance approvals are in place and all of the biosafety and agent-specific training have been conducted, will the research projects be initiated. Only then can the preliminary data be generated to support research grant applications to federal agencies. The development of a funding stream to the RBL based on research grants is a very slow and laborious process.

Putting the "regional" in regional biocontainment laboratories

Construction of the BRI is finished and that of the RBLs is largely accomplished (although many have not yet initiated operations until the appropriate federals approvals [i.e. CDC Select Agent]) are in place. It is obvious that as these facilities begin operations, space will be available for researchers outside the host university to conduct infectious disease research. University researchers, as well as those in the private sector, will have opportunities to conduct research or evaluate therapeutics or vaccines that would be either impossible in their home institutions owing to a lack of biocontainment space or difficulties in scheduling space in over-subscribed small individual biocontainment labs. One path for this activity would be to establish a formal collaboration with a faculty member at the RBL host institution. The limited number of biocontainment-related investigators initially at the RBL host institution, however, limits this approach. A more fruitful initial approach would be for the RBL host institutions to contract out the use of its biocontainment facilities and technical expertise to regional universities and biotech or pharmaceutical companies. The RBL would not only provide the facilities and specialized equipment necessary to conduct the studies, but would provide a trained technical staff as well. The advantages to this approach to the outside investigator would be not having to provide the federal regulatory clearances for lab workers, not having to train lab personnel in techniques which may not be totally familiar to the investigator, and not having to secure housing for the researchers during the duration of the experiments.

The biocontainment facility host institutions will have to develop business plans to facilitate these contract services. Fee for service rates would have to be established. Marketing approaches would have to be established and web sites developed to effectively inform researchers from both academic institutions and the private sector about the capabilities of the biocontainment facility and the types of expertise resident in the facility. Development of effective business and marketing strategies is beyond the expertise of the scientists conducting 
infectious disease research, so it is imperative that the Universities mobilize the requisite expertise from other sectors of the university. It is also important that university officials of the RBL host institution maintain open lines of communication with the other regional research universities so that when opportunities for research interactions arise, the institutions involved will be able to respond quickly to these.

Impediments to regional cooperation

Time is the biggest concern when establishing cooperative research agreements involving biocontainment facilities. Once an agreement between institutions is reached, a long list of approvals at both the federal and local levels is required. If select agent organisms are involved, approval by the CDC and/or the USDA is required. The RBL would have to gain approval for working with the specific agent, if approval for that particular organism is not in place. Agent-specific standard operating procedures would have to be developed and agent-specific training of the RBL personnel instituted. At the host university level, project applications to the research compliance committees, the IBC and ACUC committees. Getting proposals approved by these federal and university committees can take months to achieve. University research compliance committees will be placed in a relatively unique position of evaluating proposals for projects originating from outside the university. University Research Offices will have to develop policies to effectively handle these occurrences. The establishment of inter-university agreements whereby the institutions would accept the compliance approvals from the other university would greatly streamline this approval process. Institutions lacking containment facilities may not have the requisite biosafety expertise on their research compliance committees. In these cases, a full review by the RBL host university would be necessary.

Another issue which could slow down the agreement process, especially when dealing with private sector companies, is the handling of intellectual property issues. This is especially important when research involving potential therapeutic agents or vaccines is conducted. Again it is imperative that the RBL host university have in place personnel and procedures to act on these issues in a timely manner.

\section{Summary}

The RBL network can become a major resource to universities and provide the necessary research environment to advance our knowledge of biothreat and emerging infectious disease agents. With the large number of diseases arising naturally in the past twenty years (Mother Nature being the ultimate bioterrorist), these facilities will play a vital role in protecting American public health in the years to come. However, to effectively utilize these facilities, researchers must learn to establish research ties with these specialized facilities and the RBL host university must establish effective lines of communication with regional universities and private sector companies to facilitate cooperative research agreements. Regional biocontainment laboratories should be truly regional and universities must 
learn to be less territorial in dealing with their sister institutions. The biocontainment facilities should be a source of new opportunities and if managed correctly, not a fiscal drain on the host university.

\section{References}

1. Atlas, R.M. 2002. Bioterrorism: from threat to reality. Ann. Rev. Microbiol. 56:167-185.

2. http://grants.nih.gov/grants/guide/rfafiles/RFA-AI-04-032.html

3. http://www.cdc.gov/selectagent/index.ht $\mathrm{ml}$

4. http://www3.niaid.nih.gov/LabsAndRes ources/resources/rce 